\title{
TOWARDS AN UPDATED REASONING FORMAL THEORY
}

\author{
[RUMO A UMA TEORIA FORMAL DO PENSAMENTO ATUALIZADA]
}

\author{
Miguel López-Astorga *
}

\begin{abstract}
In the late twentieth century, the final version of the mental logic theory was presented. That was a syntactic and formal approach intended to describe and explain the human inferential ability. Maybe because of several experimental results achieved during the last years that have not addressed by the theory, it can be thought that its framework is outdated today. In this paper, I try to update some particular aspects of the mental logic theory by taking recent empirical evidence and arguments coming from the specialized literature into account. Such aspects refer to the symbols that it should adopt, its actual essential schemata, and the way in which the theory can deal with denials.
\end{abstract}

KEYWORDS: formal schemata; inference; mental logic; reasoning; syntax
RESUMO: No final do século XX, a versão final da teoria lógica da mente foi apresentada. Ela era constituída por uma aproximação formal e sintática que objetivava descrever e explicar a habilidade de inferências humanas. Tendo em vista vários resultados experimentais obtidos nos últimos anos que fogem ao escopo desta teoria, podemos afirmar que ela, hoje, encontrase desatualizada. Neste artigo, objetivamos atualizar alguns aspectos particulares da teoria lógica da mente em relação com evidências empíricas recentes e argumentos oriundos da literatura especializada. Tais aspectos se referem aos símbolos que ela deveria adotar, ao esquema essencial e ao modo no qual ela pode conviver com suas negações

Palavras-chaVe: Esquemas formais; inferência; lógica mental; pensamento; sintaxe

\section{INTRODUCTION}

$\mathrm{T}$

he proponents of the mental logic theory provided its last version in 1998, in particular, in the book edited by Martin Braine and David O'Brien that very year (Braine \& O'Brien, 1998a). It is true that a part of the theory was not finished in that work. That part is the one related to the mental predicate logic (the book basically only offers a possible proposal of a mental predicate logic and some of empirical evidence supporting that proposal; see Braine, 1998; Yang, Braine, \& O’Brien, 1998). However, the most important part of the framework, i.e., the part referring to the mental propositional logic does seem to be absolutely completed if all of the chapters of the book are taken into account. In this way, the final text presented by Braine and O'Brien shows a syntactic or formal theory that, to a large extent, is able to account for human reasoning.

Nevertheless, the theory appears to have certain difficulties at present. Although

* Ph.D. in Philosophy by Universidad de Cádiz (España). Áreas UNESCO: Lógica, Filosofía de la Ciencia. Professor at the Institute ofHumanistic Studies "Juan Ignacio Molina," University of Talca,Chile.m@ilto:milopez@utalca.cl 
the adherents of the theory have written and published works after 1998, some of them being relatively recent (e.g., O'Brien, 2009, 2014; O'Brien \& Li, 2013; O'Brien \& Manfrinati, 2010), the basic theses, principles, and requirements of the theory continue to be the same. And this is a problem because many experiments have been carried out and a lot of empirical results have been obtained since that date, which have not been

12 considered by the theory. This circumstance can lead one to think that it is not updated, since it has not done the same as other alternative rival theories, which have improved and developed their frames from experimental data. So, it can be said that today there are a number of difficulties in cognitive science field that, while other approaches can somehow explain them, they have not even been addressed by the mental logic theory. And it can be added to all of this that some of the fundamental theses of the theory can be reviewed, discussed, and simplified. Nonetheless, of course, this last work has not been done either and, as said, the mental logic theory remains without great changes or modifications since 1998 .

Maybe the aspects to correct or improve are a lot (see, e.g., López-Astorga, 2014a, 2015a, 2016a). But, in this paper, I will only consider three particular points. One of them is linked to the symbols to use in the theory. This can appear to be a purely aesthetic and not important issue. However, in my view, as argued below, it is clearly relevant, since the logical systems often seem to depend on the language spoken by their authors. Nonetheless, this should not be the case of the mental logic theory. And the reason is that, based on theses such as those of Fodor (1975) or Macnamara (1986), the mental logic theory tries to identify the real rules of the syntax of thought (see, e.g., Braine \& O'Brien, 1998b; O'Brien \& Li, 2013), i.e., of a deep syntax that is common to all of the languages around the world. In this way, an actual mental logic should not be linked to any language in any way, although such languages are languages so related to philosophy or science as ancient Greek or English.

A second point that will be dealt with here is the one of the number of schemata accepted by the theory. The mental logic approach provides seven 'Core Schemata,' that is, seven basic formal rules that the human mind can apply very easily. My proposal, nevertheless, is that, if it is assumed that individuals understand what disjunction exactly is, it is clear that two of those rules are really the same. On the other hand, if we actually assume that idea, i.e., that individuals usually understand the general characteristics of disjunction, it can also be stated that a third Core Schema is trivial as well and can be removed. The final result is, in this way, that perhaps there are only five Core Schemata on the human mind. Undoubtedly, this is a very important aspect because, if what is being proposed is, as said, a syntax of thought, that syntax needs to be as simple as possible.

And finally, I will comment on the way that a formal theory as the mental logic theory can work with negated propositions. There is little information concerning this point in the original papers and chapters authored by adherents of the mental logic theory. Nonetheless, I will try to develop it with the help of works in which this has been already studied, for example, López-Astorga (2014b, 2016b).

But, before doing all of this, it seems to be opportune to explain in more details which the main theses of the mental logic theory are. This last explanation will be given in the next section, which essentially will describe the 1998 version of the theory. In this regard, to avoid confusions, from now on, I will refer to this later version with the abbreviation '98ML' (1998 Mental Logic). On the other hand, I will call my new version 'RFT' (Reasoning Formal Theory).

\section{ML89}

ML98 is not the only formal or syntactic theory on human reasoning. It can be said that there have been several approaches claiming that the human mind works following formal schemata. That can be, for example, the case of the system proposed 
by Gentzen (1935) and all of the theories that have held the idea that our reasoning abilities are somehow related to rules akin to those of standard propositional calculus, including frameworks such as that of Beth and Piaget (1966), Henlé (1962), or Rips $(1994,2011)$. Of course, all of these systems are different from each other, and 98ML is also different from all of them. In particular, this later theory states that human reasoning makes inferences in accordance with formal rules being valid in standard logic, but it does not admit all of the rules being correct in this last logic. In addition, $98 \mathrm{ML}$ claims that all of the rules of the human mind do not play the same role in reasoning. The selection of rules is strictly based on empirical evidence, which means that $98 \mathrm{ML}$ only accepts that a logical rule is a natural schema on the human mind if there are experimental results showing that. Thus, the theory proposes that there are a number of Core Schemata that "....are used without restriction whenever they are applicable" (Braine \& O'Brien, 1998c, pp. 79-83), that is, they are "the schemata that people apply in all the occasions in which it is possible to do it" (López-Astorga, 2016b, p. 124). A clear example of Core Schema is Modus Ponendo Ponens, i.e., one of the $\alpha$ va $\alpha$ ó $\delta \varepsilon \imath \kappa \tau o l$ (indemonstrables) related to the conditional already detected by the Stoic philosopher Chrysippus of Soli (Diogenes Laërtius, Vitae Philosophorum 7.80), and which, according to 98ML (Braine \& O'Brien, 1998c, p. 80; Table 6.1), is Schema 7 in the theory. As is well known, its structure is:

$$
\begin{aligned}
& \text { IF A THEN B } \\
& \text { A } \\
& - \text { Ergo B }
\end{aligned}
$$

On the other hand, another type of schema is that of 'Feeder Schemata.' These schemata "... are used only when their output feeds another schema..." (Braine \& O'Brien, 1998c, p. 83). So, "these schemata are only applied when their use can allow drawing conclusions" (López-Astorga, 2016b, p. 124). The two most important Feeder Schemata are the primitive rules that standard propositional calculus assigns to conjunction, i.e., the rules to introduce and remove conjunctions. As is also well known (see, e.g., Deaño, 1999, p. 154), these rules can be expressed as follows:

$$
\begin{aligned}
& A \\
& B \\
& \hdashline \text { Ergo A AND B }
\end{aligned}
$$

\section{$A A N D B$}

$\operatorname{Ergo} A$

These rules are similar to schemata 8 and 9 of $98 \mathrm{ML}$ respectively (see Braine $\&$ O’Brien, 1998c, p. 80; Table 6.1).

A third type is the one of 'Incompatibility Schemata,' that is, of the schemata that “...define contradictions” (Braine \& O’Brien, 1998c, p. 83). They “...show that a contradiction has been found and that, therefore, at least one of the assumptions is false" (López-Astorga, 2016b, p. 125). In this case, an evident and obvious example is the following: 
$A$

Not A

Ergo INCOMPATIBLE

This argument is similar to Schema 10 of 98ML (see Braine \& O'Brien, 1998c, p. 81; Table 6.1). However, what is important about it here is that its role is very different from the one that contradiction plays in standard calculus. In this later calculus, contradictions are linked to both Reductio ad Absurdum (i.e., the strategy consisting of supposing the contrary of what is wished to demonstrate and, if a contradiction is found, concluding the denial of the supposition) and the principle of explosion (i.e., the principle that provides that Ex Contradictione Quodlibet Sequitur, that is, that given a contradiction, any conclusion follows). Nevertheless, in 98ML, they are only related to the former. Although with certain restrictions, the theory states that individuals can use the strategy of Reductio ad Absurdum to prove that a particular assumption is not possible along with a given set of premises. What the theory does not admit is that any formula can be deduced from an incompatibility, and it does not accept this simply because, as shown by empirical evidence, the human mind does not work in this way. This is a very relevant point that distinguishes $98 \mathrm{ML}$ from standard logic, and that appears to make it akin to paraconsistent logics such as that of Bolzano (1837). In fact, because of this characteristic, based on Woods and Irvine (2004), López-Astorga (2016a) compares 98ML even with Aristotelian logic and finds certain problems that the theory needs to solve.

But, if the aims of this paper are taken into account, what has been said about $98 \mathrm{ML}$ can be enough to have an overall view of it. Maybe it is only necessary to add that the theory also admits other schemata, which, however, are not considered to be so essential and their use is not always guaranteed. According to the theory, some individuals are more sophisticated than others, and the most sophisticated individuals are more likely to apply those other schemata. They can even use more schemata that the theory does not consider and that, nevertheless, are valid in standard logic.

All of this said, it seems that it is already possible to address my main goals here. As mentioned, the first one of those goals refers to the fact that a mental logic theory needs distinctive symbols that are not linked to any language. The next section deals with this point.

\section{A PROPOSAL OF SYMBOLS FOR RFT}

As also indicated, this is not just an aesthetic problem. A syntax of thought cannot have linguistic influences coming from any particular culture. Nonetheless, the problem is ancient. For example, the Greek logicians tended to use words in their language performing the function of connectives similar to those of current logic. In this way, it is not hard to find that, in sources such as Vitae Philosophorum (by Diogenes Laërtius), Adversus Mathematicos or Pyrrhoneae Hypotyposes (both of them by Sextus Empiricus), the word $\varepsilon i$ (if) is used to refer to the conditional, the word $\kappa \alpha i$

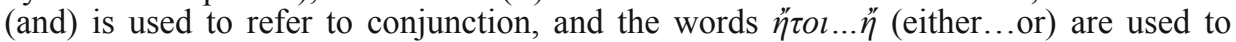
refer to disjunction.

Unfortunately, 98ML does something similar, since, although in capital letters, it also resorts to the English words 'IF', 'AND', and 'OR' to refer to the conditional, conjunction, and disjunction respectively. As stated, this does not appear to be adequate, since it seems to provide the existence of certain links between English and the syntax of thought, and this later syntax should be independent of any language, whether it is modern or ancient. But, on the other hand, that seems to be wrong too from another 
point of view. Many examples of sentences expressing conditional, conjunctive, or disjunctive relationships without using the habitual words (in English, as said, 'if', 'and', and 'or') are to be found in different languages. An obvious English example in this way can be the following sentence:

Whenever I go to the cinema, I eat popcorn

Although this sentence does not include the word 'if,' there is no doubt that it indicates a conditional relationship between going to the cinema and eating popcorn. In fact, an alternative way to express it meaning the same could be as follows:

If I go to the cinema, then I eat popcorn

So, all of this advises the use of symbols, and not of words taken from a particular language. Of course, one might think that, although this is truly the case, it is not necessary to invent or create new symbols, since standard logic already has them. However, the use of the symbols of standard logic (or of all of them) does not appear to be appropriate either. The reason is that the operators of $98 \mathrm{ML}$, and hence of RFT, do not have necessarily the same properties as the operators of standard logic. For example, neither 98ML nor, in the same way, RFT accept the material interpretation of the conditional, i.e., the interpretation of it given by Philo of Megara (see, e.g., O'Brien, 2014; López-Astorga, 2015b). Likewise, they do not consider the disjunction introduction rule, that is, the rule that allows deriving 'A or B' from 'A,' to be valid (see, e.g., Braine \& O’Brien, 1998a; López-Astorga, 2015a). And it must be added to examples such as those ones that to use the symbols of standard logic could cause confusions between this later logic and systems such as 98ML or RFT.

So, apart from the denial, whose meaning in 98ML and RFT is not very different from the one attributed to it in standard propositional calculus, and which could be stood for by the symbol ' $\neg$,' the symbols that I propose to RFT and its properties are the following:

\section{- Conditional: ‘:-‘}

This symbol represents every relation between two sentences indicating that, if what is expressed by one of them (which is placed on the left side of the symbol and can be called 'antecedent') is true or happens, then what is expressed by the other one (which is placed on the right side of the symbol and can be called 'consequent') is true or happens too.

\section{- Conjunction: '•’}

This symbol refers to the fact that the two sentences linked by it are true.

\section{- Disjunction: ':’}

This symbol indicates that at least one of the sentences linked by it is true.

As it can be noted, these symbols are not directly related to any word in natural language, whether that language is English or any other one. They just try to reflect the three basic relationships between sentences that exist in the syntax of thought. And a very important point in this regard is that, in addition to the fact that what is expressed in that syntax can be expressed in very different ways by means of different languages, as commented on, it can expressed in several ways in the same language as well. Therefore, giving further details about those symbols may not be appropriate. Perhaps what does be important is to include one more symbol to denote deduction or derivation relation. That symbol can be ':-:', and its meaning can be that the right formula can be drawn from the left formula or formulae. 
This can be enough as far as the symbols of RFT are concerned. From now on, they will be used in this paper, whose next section addresses the problem of the number of Core Schemata in 98ML.

\section{The five Core Schemata of RFT}

As said, 98ML has seven Core Schemata. However, in my view, all of them are not equally basic. On the one hand, two of them can be considered to be the same. One of these two schemata is Core Schema 5 in Braine and O'Brien (1998c, p. 80; Table 6.1), and can be expressed with RTF symbols as follows:

$$
[(A: B) ;(A:-C) ;(B:-C)]:-: C
$$

And the other one is Core Schema 6 in Braine and O'Brien (1998c, p. 80; Table 6.1 ), and, in RFT symbols, could be similar to this one:

$$
[(A: B) ;(A:-C) ;(B:-D)]:-:(C: D)
$$

Obviously, in the last two formulae, the square brackets contain the premises, which are separated by semicolons, and the formula on the right side of the symbol of deduction (:-:) is the conclusion. As stated, it can be thought that those two formulae do not truly stand for different schemata. If we assume that there is a syntax of thought, that a central element of that syntax is disjunction, and that people hence use to understand correctly the disjunctive relationships, it is evident that Core Schema 5 of $98 \mathrm{ML}$ can be removed. Indeed, if that schema is not, what an individual can derive from a premises set such as [(A : B); (A :- C); (B :- C)] is just, by virtue of Core Schema $6,(\mathrm{C}: \mathrm{C})$. But, if, as assumed, that individual understands what disjunction really means, he (or she) knows that $(\mathrm{C}: \mathrm{C})$ is in fact equivalent to $(\mathrm{C})$. So, Core Schema 5 seems clearly trivial.

Nevertheless, the idea that individuals know all disjunction implies also leads to reject another Core Schema of $98 \mathrm{ML}$. That is Core Schema 2 in Braine and O'Brien (1998c, p. 80; Table 6.1), and can be formally expressed in RFT symbols in this way:

$$
\{[(A: B):-C] ; B\}:-: C
$$

Understanding disjunction is knowing that a sentence such as (A : B) is true whenever at least one of the two disjuncts (A or B) is true. So, given that the second premise of the previous schema provides that the second disjunct of the antecedent of the first premise, i.e., (B), is true, it is clear that that antecedent is true too. And, therefore, by virtue of Modus Ponendo Ponens, which is, as said, Core Schema 7 of $98 \mathrm{ML},(\mathrm{C})$, the conclusion, is true as well.

Thus, we have a more basic syntax of thought, since it includes only five Core Schemata now, which would be Schemata 1, 3, 4, 6, and 7 in Braine and O'Brien (1998c, p. 80; Table 6.1), and could be expressed in RFT symbols as follows:

$$
\begin{aligned}
& C S 1=\neg \neg A:-: A \\
& C S 2=[(A: B) ; \neg A]:-: B \\
& C S 3=[\neg(A \cdot B) ; A]:-: \neg B \\
& C S 4=[(A: B) ;(A:-C) ;(B:-D)]:-:(C: D)
\end{aligned}
$$




$$
C S 5=[(A:-B) ; A]:-: B
$$

Where 'SC' means 'Core Schema,' and the number following refers to the new number that corresponds to the schema in the RFT version.

These would hence be the Core Schemata of RFT, which clearly show that this later theory is heir to different frameworks and approaches. Of course, as stated, it is basically a new version of $98 \mathrm{ML}$, which is in turn means that it takes important and relevant elements of standard propositional calculus and Gentzen's (1935) system. But there is also an evident relationship to a much older logic: Stoic logic. True, four of the five Core Schemata of RFT come directly from this later logic. CS1 refers to the double negation, and that an expression such as $(\neg \neg$ A) is equivalent to (A) was an idea already held by Stoicism, which spoke about the $\dot{\pi} \pi \varepsilon \rho \dot{\alpha} \pi о \varphi \alpha \tau \imath \kappa o ́ v$ (Diogenes Laërtius, Vitae Philosophorum 7.69; Barnes, Bobzien, \& Mignucci, 2008, p. 102). Secondly, CS2 is

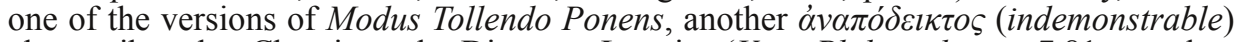
also attributed to Chrysippus by Diogenes Laërtius (Vitae Philosophorum 7.81; see also, e.g., fragment 9.7 in Boeri \& Salles, 2014, pp. 216-217 \& 228-229; López-Astorga, $2015 \mathrm{c}$, pp. 3-4). On the other hand, CS3 is a Chrysippus' indemonstrable too, in particular, a version of Modus Ponendo Tollens (e.g., Diogenes Laërtius, Vitae Philosophorum 7.80; fragment 7 in Boeri \& Salles, 2014, pp. 216-217 \& 228-229; López-Astorga, 2015c, p. 6). And, finally, it has already said twice that CS5 is Modus Ponendo Ponens (see also, e.g., the same fragment in Boeri and Salles, 2014, or LópezAstorga, 2015c, p. 3).

So, it is obvious that the greatest debt owed by RFT is a debt contracted with Stoic philosophy (as far as 98ML is concerned, a study of the relations between this later framework and the Stoic indemonstrables can be found in López-Astorga, 2015c). However, another aspect important for the theory is how it can deal with negations. The truth is that, as far as I know, there are no a lot work carried out in this regard. Nevertheless, relatively recent researches can help in this way. Such researches are made from a perspective different from RFT, but, as shown below, its results can be assumed by this later approach.

\section{RFT AND DENIALS}

Actually, the experimental results that can be used to complete RFT with respect to the way it can address negations come from works supporting a rival theory, the mental models theory (e.g., Byrne \& Johnson-Laird, 2009; Johnson-Laird, 2015; Johnson-Laird, Khemlani, \& Goodwin, 2015; Khemlani, Lotstein, Trafton, \& JohnsonLaird, 2015; Khemlani, Orenes, \& Johnson-Laird, 2012, 2014). This theory is semantic and proposes that human beings make inferences taking the semantic meaning of the sentences and pragmatics factors into account, and not their logical forms. Nonetheless, explaining the general theses of this framework would move us away from the aims of this paper. If such aims are considered, what is interesting here is only the empirical information obtained in the studies carried out by proponents of the mental models theory, regardless of how such proponents interpret those results. Furthermore, comparisons between $98 \mathrm{ML}$ and the mental models theory can be easily found in the literature of cognitive science (e.g., López-Astorga, 2014b, 2015a, 2015b, 2015d).

Thus, a paper with results very relevant for my goals is that of Macbeth, Razumiejczyk, Crivello, Bolzán, Pereyra Girardi, \& Campitelli (2014). In that work, the authors present certain experimental results that, according to them, are consistent with the mental models theory. That is correct and I will not discuss it here. In fact, that discussion has been already addressed by López-Astorga (2014b). What is important for this paper is that such results show that DeMorgan's (1847) are not equally hard to understand for people, and this is a fact that a theory such as RFT needs to take into 
account.

One of those results is that DeMorgan's law denying a disjunction is very easy for individuals. That law can be expressed in RFT symbols in a following way:

$$
\neg(A: B)=\neg A \cdot \neg B
$$

Indeed, the experiment proposed by Macbeth et al. (2014) included sentences with thematic content matching those formal structures and they noted that people really are aware of the equivalence. According to López-Astorga (2014b), a possibility is that $98 \mathrm{ML}$ assumes the equivalence as a schema, and I agree with that. But this raises a problem and has a consequence. The problem is that, as indicated by López-Astorga (2014b, p.27), if admitted, it would be necessary to make a decision on which type of rule this schema is. There are different possibilities, but the most adequate seem to be it is a Core Schema or a Feeder Schema. In my view, although people often understand the equivalence, individuals only make cognitive efforts when necessary. For that reason, in principle, it appears to be a better option to assume the law as a Feeder Schema that is applied only when its use can enable to draw further conclusions.

Nevertheless, to add this law as a Feeder Schema can really mean to add two schemata, since the equivalence can be understood in the two directions. Thus, the final result would be hence that RFT has four Feeder Schemata, which, in the symbols of this later system, would be these ones:

$$
\begin{aligned}
& F S 6=(A ; B):-:(A \cdot B) \\
& F S 7=(A \cdot B):-: A \\
& F S 8=\neg(A: B):-:(\neg A \cdot \neg B) \\
& F S 9=(\neg A \cdot \neg B):-: \neg(A: B)
\end{aligned}
$$

Obviously, 'F' refers here to 'Feeder.'

As it can be noted, FS6 and FS7 are the Feeder Schemata indicated above, and FS8 and FS9 are the two versions of the DeMorgan's law that people use to interpret correctly. Maybe it is also important to highlight that the results achieved by Macbeth et al. (2014) were confirmed and supported in other studies too, for example, in that of Khemlani et al. (2014). Circumstances such as this one justify to a greater extend the inclusion of FS8 and FS9 in RFT, and make it clear that denied disjunctions are not a problem for this later framework. As indicated, people tend to interpret them in a right way.

But, as said, this also raises a consequence. 98ML proposes two Incompatibility Schemata. That mentioned above and, in RFT symbols, this one:

$$
[(A: B) ;(\neg A \cdot \neg B)]:-:><
$$

Where ' $><$ ' means 'incompatibility', 'contradiction', or 'inconsistency.'

As it can be easily seen, FS9 makes this schema trivial and superfluous, since it can transform the second premise into $\neg(\mathrm{A}: \mathrm{B})$, which in turn makes it a simple version of Incompatibility Schema 10 of $98 \mathrm{ML}$, and allows removing it. In this way, it could be assumed that the only Incompatibility Schema of RFT is Schema 10 of 98ML, which can be expressed in the symbols of the former as follows: 


$$
I S 10=(A ; \neg A):-:><
$$

And the ten schemata indicated so far could be the fundamental or basic schemata of RFT, since, although 98ML admits, as commented on, other schemata, they have restrictions and are not always applied. Likewise, they can depend on individuals' sophistication level.

However, this does not mean that there are not further difficulties. The experimental results concerning denied disjunctions can be assumed by RFT without great problems, but the case of denied conjunctions is different. As is well known, there is another law proposed by DeMorgan:

$$
\neg(A \cdot B)=\neg A: \neg B
$$

The problem with this law is that Macbeth et al. (2014) carried out experiments on it as well and the results were not positive. They noted that people tend not to understand correctly this law. Likewise, Khemlani et al. (2014) came to similar results, another important datum obtained with their research being that individuals often interpret $\neg(\mathrm{A} \cdot \mathrm{B})$ as $(\neg \mathrm{A} \cdot \neg \mathrm{B})$, i.e., in exactly the same manner as $\neg(\mathrm{A}: \mathrm{B})$. But, as far as this point is concerned, papers such as those of López-Astorga (2014b, 2016b) are very interesting. His position is initially that, given that $98 \mathrm{ML}$ has no predictions about DeMorgan's laws, results such as those do not have an influence on its fundamental and basic theses. Nevertheless, López-Astorga also proposes that it is very possible that people do tend to interpret $\neg(\mathrm{A} \cdot \mathrm{B})$ and $\neg(\mathrm{A}: \mathrm{B})$ in a similar way, that is , as $(\neg \mathrm{A} \cdot \neg \mathrm{B})$ (see López-Astorga, 2016b, pp. 132-133). In my view, this later idea can be assumed without difficulties, since, if we review the sentences used by both Macbeth et al. (2014) and Khemlani et al. (2014) in their experiments, we can see that such sentences are very odd in English (and probably in any language that they are translated into).

For example, one of those of Macbeth et al. is "IT IS NOT TRUE THAT: LONDON IS A CITY AND AFRICA IS A CONTINENT" (Macbeth et al., 2014, p. 141; Table 2; capitals in text. See also López-Astorga, 2014b, p. 25). Obviously, this sentence is hard to understand because, although it really has the formal structure $\neg(\mathrm{A}$. $\mathrm{B})$, it is not a habitual sentence in daily life conversations, and what it actually seems to mean is that neither London is a city nor Africa is a continent. In this way, its real structure appears to be $(\neg \mathrm{A} \cdot \neg \mathrm{B})$. Something similar happens with the sentences used by Khemlani et al. (2014). One of them was akin to this one: 'Bob denied that he wore a yellow shirt and he wore blue pants on Monday' (see Khemlani et al. 2014, p. 4; see also López-Astorga, 2016b, p. 126). Again, the sentence appears odd for people and it is not clear which its true meaning is. In fact, it can be easily thought that what it truly means is that Bob wore neither yellow shirt nor blue pants on Monday, i.e., that its formal structure is $(\neg \mathrm{A} \cdot \neg \mathrm{B})$ as well.

Therefore, López-Astorga's idea appears to make sense. He even takes into account a possible criticism against his argument. That criticism is that, if $98 \mathrm{ML}$ includes a schema such as Schema 4 in Braine and O'Brien (1998c, p. 80; Table 6.1), which would be, as indicated, CS3 in RFT, that means that, according to the theory, people should understand and correctly interpret denied conjunctions. Nonetheless, the López-Astorga's response against this possible criticism is that, in that schema, it appears not only a denied conjunction. It also includes a second premise in which it is stated that one of the conjuncts really happens and is true, which blocks the possibility to interpret $\neg(\mathrm{A} \cdot \mathrm{B})$ as $(\neg \mathrm{A} \cdot \neg \mathrm{B})$, since the second premise shows that one of the conjuncts is not false (López-Astorga, 2016b, p. 133).

However, be that as it may, the truth is that it does not seem an important problem for RFT. And it does not seem that at least for two reasons. Firstly, as said, the expressions in natural languages referring to denied conjunctions are very odd in daily life. Secondly, while it is necessary to correctly interpret expressions such as $\neg(\mathrm{A}: \mathrm{B})$, it 
is not so important to appropriately understand expressions such as $\neg(\mathrm{A} \cdot \mathrm{B})$. And this is so because, while the theory has no rule to work with denied disjunctions, it does have a schema to work with denied conjunctions (CS3).

Furthermore, as shown, RFT considers empirical results coming from the literature. So, given that people tend to adequately interpret denied disjunctions, it assumes schemata such as FS8 and FS9. But, given that that does not happen in the case of denied conjunctions, it does not accept similar schemata involving sentences with the structure $\neg(\mathrm{A} \cdot \mathrm{B})$.

Finally, the remaining connective, the conditional, is not a problem when denied. Khemlani et al. (2014) carried out experiments in this regard and find that, while people can deny conditionals in two different ways, as $\neg(\mathrm{A}:-\mathrm{B})$ and as (A :- $\neg \mathrm{B})$, which, as indicated by them and López-Astorga (2016b), was already researched in works such as, e.g., Byrne and Johnson-Laird (2009) and Handley, Evans, and Thompson (2006), they always understand that the denial means that scenarios in which the antecedent is true and the consequent is so as well are not possible. Their experiments tried to detect which the scenarios that people consider to be consistent with a denied conditional are, and the two majority response patterns were these ones:

-Three scenarios: $A$ and $\neg B, \neg A$ and $\neg B$, and $\neg A$ and $B$. -Just one scenario: $A$ and $\neg B$.

Evidently, these results are important for the mental models theory and have a clear meaning under its framework. But what is interesting for us in this paper is that they are also important for RFT and have a clear meaning under its framework too. Based on them, something is obvious: as indicated, if we deny a sentence such as (A :$\mathrm{B})$, there is no doubt that that means that, if A happens, B cannot occur as well. And this is absolutely coherent with what has been said on the conditional above. If (A :- B) stands for the situation in which, when A happens, B must happen too, $\neg$ (A :- B) stands for the situation in which, when $\mathrm{A}$ happens, $\neg \mathrm{B}$ must happen too. And from this perspective, it can be claimed that, in RFT view, it does not matter whether the denial of the conditional is interpreted as $\neg(\mathrm{A}:-\mathrm{B})$ or as $(\mathrm{A}:-\neg \mathrm{B})$. It always means that B will never be possible if $\mathrm{A}$ is true. Thus, it can be stated that, both from $\neg(\mathrm{A}:-\mathrm{B})$ and $\mathrm{A}$, and from $(\mathrm{A}:-\neg \mathrm{B})$ and $\mathrm{A}, \neg \mathrm{B}$ can derived.

It is true that, while the second case, i.e., that in which the premises are (A :- $\neg \mathrm{B})$ and A, is a clear application of Modus Ponendo Ponens, the second one appears to be more problematic. In fact, it could be thought that maybe it would be necessary a new schema that allowed transforming, for example, $\neg$ (A :- B) into (A :- $\neg$ B). However, it can also be thought that more schemata can unnecessary complicate the theory, and that derive $\neg \mathrm{B}$ from $\neg(\mathrm{A}:-\mathrm{B})$ and $\mathrm{A}$ is an evident use of Modus Ponendo Ponens too. If the conditional is false and we have the antecedent $(\mathrm{A})$, the obvious conclusion is that the consequent is also false. In this regard, the only additional modification that would be needed would be that it must be acknowledged that the schemata of RFT can be expressed in different ways. For example, there is no doubt that FS7 not only enables to draw A from (A - B), but also B. And this is not explicitly said because is trivial. Likewise, there is no doubt that CS5 not only enables to derive B from (A :- B) and A, but also $\neg \mathrm{B}$ from $\neg(\mathrm{A}:-\mathrm{B})$ and $\mathrm{A}$. And this is not explicitly said because is trivial as well.

\section{Conclusions}

It hence is obvious that the idea of a mental logic on the human mind can still be considered. We cannot reject it as the general theses of systems such as 98ML alone and, of course, ML98 complemented by the characteristics presented in this paper about 
RFT have a great predictive and explanatory power. In my view, however, 98ML is outdated. Cognitive science has found new and very interesting experimental results during the last years, and the syntactic approaches such as that of $98 \mathrm{ML}$ cannot ignore them anymore.

In this way, this paper has been intended to update that theory by taking some of those empirical findings into account. The result is the ten schemata of RFT presented and explained above, i.e., a new simpler version of 98ML. I have addressed here the problem of the formalization and the symbols when we speak about a syntax of thought underlying every language around the world, as well as the problem that a logical connective can be expressed in different ways in a same language. I have also dealt with the problem that the schemata of $98 \mathrm{ML}$, on the one hand, seem a lot and, on the other hand, do not consider new information coming from the literature such as that related to DeMorgan's laws. And, likewise, I have reviewed the problem of the denials too. As far as this point is concerned, the only complicated case is, as explained, that of conjunction. Nevertheless, as also shown, its problems do not really have an influence on the theory, since it has a schema to be applied to denied conjunctions, and the sentences with denied conjunctions used in the experiments reported in the literature are often very odd.

In any case, I am aware that, of course, the proponents of 98ML may not agree with the updates introduced in this paper to the theory. Thus, they may even consider RFT to be a different framework from 98ML. That is the reason why I have preferred to use different names to the two versions. In my opinion, both systems are in essence the same and, as said, RFT is just an update of 98ML. It acknowledges, as also mentioned, the heritage it received from the Stoics in Ancient Greece, from calculi such as that of Gentzen (1935), and from approaches such as those of Beth and Piaget (1966) and Henlé (1962). RFT is neither one of these frameworks, but it has elements of all of them. And this is also exactly the case for $98 \mathrm{ML}$, whose differences with RFT are not radical or basic. So, I insist, as I understand it, the latter is only a version of the former.

\section{REFERENCES}

BARNES, J.; BOBZIEN, S.; \& MIGNUCCI, M. Logic. In: ALGRA, K.; BARNES, J.; MANSFELD, J.; SCHOFIELD, M. eds. The Cambridge History of Hellenistic Philosophy. Cambridge, UK: Cambridge University Press, pp. 77-225, 2008.

BETH, E. W.; PIAGET, J. Mathematical Epistemology and Psychology. Dordrecht, The Netherlands: Reidel, 1966.

BOERI, M. D.; SALLES, R. Los filósofos estoicos. Ontología, lógica, física y ética. Santiago de Chile, Chile: Ediciones Universidad Alberto Hurtado, 2014.

BOLZANO, B. Wissenschaftslehre. Sulzbach, Germany: Seidel Buchhandlung, 1837.

BRAINE, M. D. S. Steps toward a mental-predicate logic. In: BRAINE, M. D. S.; O'Brien, D. P. eds. Mental Logic. Mahwah, NJ: Lawrence Erlbaum Associates, Inc., Publishers, pp. 273$331,1998$.

BRAINE, M. D. S.; O'BRIEN, D. P. (eds.). Mental Logic. Mahwah, NJ: Lawrence Erlbaum Associates, Inc., Publishers, 1998a.

BRAINE, M. D. S.; O'BRIEN, D. P. How to investigate mental logic and the syntax of thought. In: BRAINE, M. D. S.; O’BRIEN, D. P. eds. Mental Logic. Mahwah, NJ: Lawrence Erlbaum Associates, Inc., Publishers, pp. 45-61, 1998 b.

BRAINE, M. D. S.; O'BRIEN, D. P. The theory of mental-propositional logic: Description and illustration. In: BRAINE, M. D. S.; O’BRIEN, D. P. eds. Mental Logic. Mahwah, NJ: Lawrence Erlbaum Associates, Inc., Publishers, pp. 79-89, 1998c.

BYRNE, R. M. J.; JOHNSON-LAIRD, P. N. "'If' and the problems of conditional reasoning." Trends in Cognitive Science, 13(7): pp. 282-287, 2009.

DEAÑO, A. Introducción a la lógica formal. Madrid, Spain: Alianza Editorial, 1999.

DeMORGAN, A. Formal Logic: Or, the Calculus of Inference Necessary and Probable. London, UK: Taylor \& Walton, 1847. 
FODOR, J. The Language of Thought. Cambridge, MA: Harvard University Press, 1975.

GENTZEN, G. "Untersuchungen über das logische Schließen I." Mathematische Zeitschrift, 39: pp. 176-210, 1935.

HANDLEY, S. J.; EVANTS, J. St. B. T.; THOMPSON, V. A. "The negated conditional: A litmus test for the suppositional conditional?" Journal of Experimental Psychology: Learning, Memory, Cognition, 32: pp. 559-569, 2006.

22 HENLÉ, M. "On the relation between logic and thinking." Psychological Review, 69: pp. 366$378,1962$.

JHONSON-LAIRD, P. N. How to improve thinking. In: WEGERIF, R.; LI, L.; KAUFMAN, J. C. eds. The Routledge International Handbook of Research on Teaching Thinking. Abingdon, UK, \& New York, NY: Routledge, pp. 80-91, 2015.

JOHNSON-LAIRD, P. N.; KHEMLANI, S.; GOODWIN, G. P. "Logic, probability, and human reasoning." Trends in Cognitive Sciences, 19(4): pp. 201-214, 2015.

KHEMLANI, S.; LOTSTEIN, M.; TRAFTON, J. G.; JOHNSON-LAIRD, P. N. "Immediate inferences from quantified assertions." The Quarterly Journal of Experimental Psychology, 68(10): pp. 2073-2096, 2015.

KHEMLANI, S.; ORENES, I.; JOHNSON-LAIRD, P. N. "Negation: A theory of its meaning, representation, and inference." Psychological Review, 109(4): pp. 646-678, 2012.

KHEMLANI, S.; ORENES, I.; JOHNSON-LAIRD, P. N. "The negation of conjunctions, conditionals, and disjunctions." Acta Psychologica, 151: pp. 1-7, 2014.

LÓPEZ-ASTORGA, M. "The conditional introduction rule and human reasoning: Findings from the mental models theory." Cogency, 6(2): pp. 29-37, 2014a.

LÓPEZ-ASTORGA, M. "The mental logic theory and DeMorgan's laws." International Journal of Humanities and Social Science, 4(11-1): pp. 24-28, 2014b.

LÓPEZ-ASTORGA, M. "The disjunction introduction rule: Syntactic and semantic considerations." Pragmalingüística, 23: pp. 141-149, 2015a.

LÓPEZ-ASTORGA, M. "The formal discipline theory and mental logic." Praxis Filosófica, 41: pp. 11-25, 2015b.

LÓPEZ-ASTORGA, M. “Chrysippus' indemonstrables and mental logic.” Croatian Journal of Philosophy, 15(43): pp. 1-15, 2015c.

LÓPEZ-ASTORGA, M. "The case of the conditionals with disjunctions embedded into their antecedents: Mental logic versus semantic models." Universum, 30(2): pp. 143-152, 2015 d.

LÓPEZ-ASTORGA, M. "The principle of explosion: Aristotle versus the current syntactic theories." Schole, 10(1): pp. 40-49, 2016a.

LÓPEZ-ASTORGA, M. "Mental logic and the denials of conjunctions and disjunctions." Trans/Form/Ação, 39(1): pp. 119-138, 2016 b.

MACBETH, G.; RAZUMIEJCZYK, E.; CRIVELLO, M. C.; BOLZÁN, C.; PEREYRA GIRARDI, C. I.; CAMPITELLI, G. "Mental models for the negation of conjunctions and disjunctions." Europe's Journal of Psychology, 10(1): pp. 135-149, 2014.

MACNAMARA, J. A Border Dispute: The Place of Logic in Psychology. Cambridge, MA: Massachusetts Institute of Technology (MIT) Press, 1986.

O'BRIEN, D. P. "Human reasoning includes a mental logic." Behavioral and Brain Sciences, 32: pp. 96-97, 2009.

O'BRIEN, D. P. "Conditionals and disjunctions in mental-logic theory: A response to Liu and Chou (2012) and to López-Astorga (2013)." Universum, 29(2): pp. 221-235, 2014.

O'BRIEN, D. P.; LI, S. "Mental logic theory: A paradigmatic case of empirical research on the language of thought and inferential role semantics." Journal of Foreign Languages, 36(6): pp. 27-41, 2013.

O'BRIEN, D. P.; MANFRINATI, A. The mental logic theory of conditional proposition. In: OAKSFORD, M.; CHATER, N. eds. Cognition and conditionals: Probability and Logic in Human Thinking. Oxford, UK: Oxford University Press, pp. 39-54, 2010.

RIPS, L. J. The Psychology of Proof: Deductive Reasoning in Human Thinking. Cambridge, MA: Massachusetts Institute of Technology (MIT) Press, 1994.

RIPS, L. J. Lines of Thought: Central Concepts in Cognitive Psychology. New York, NY: Oxford University Press, 2011.

WOODS, J.; IRVINE, A. Aristotle's early logic. In: GABBAY, D. M.; WOODS, J. eds. Handbook of the History of Logic, Volume 1. Greek, Indian and Arabic Logic. Amsterdam, The Netherlands: Elsevier, pp. 27-99, 2004.

YANG, Y.; BRAINE, M. D. S.; O'BRIEN, D. P. Some empirical justification of the mentalpredicate-logic model. In: BRAINE, M. D. S.; O'BRIEN, D. P. eds. Mental Logic. Mahwah, NJ: Lawrence Erlbaum Associates, Inc., Publishers, pp. 333-365, 1998. 